Resenha do livro:

DUARTE, Newton. Sociedade do Conhecimento ou Sociedade das ilusões? quatro ensaios crítico-dialéticos em filosofia da educação. Campinas: Autores Associados, 2008.

Resenha de:

Gilberto César Lopes Rodrigues ${ }^{1}$

UFOPA

\title{
SOCIEDADE DO CONHECIMENTO COMO ALIENAÇÃO DOS SABERES HISTORICAMENTE ELABORADOS PELA HUMANIDADE
}

No livro Sociedade do Conhecimento ou Sociedade das ilusões Newton Duarte reúne quatro textos, transformados em capítulos, que resultam de pesquisas realizadas no âmbito da filosofia da educação. Neles o autor analisa questões educacionais postas pela sociedade contemporânea em uma perspectiva crítico-dialética objetivando mostrar a validade, atualidade, consistência e força que o marxismo reúne, de sobra, para fazer frente ao pós-modernismo e ao neoliberalismo no campo da educação.

No primeiro capítulo intitulado As pedagogias do 'Aprender a Aprender' e algumas ilusões da assim chamada sociedade do conhecimento o autor apresenta sua concepção de que a alcunha amplamente usada para designar a sociedade atual de sociedade do conhecimento não passa de um fenômeno no campo da reprodução ideológica ilusionária do capitalismo, cujo papel seria o de enfraquecer as críticas radicais ao capitalismo, dificultando sua superação.

Depreende-se da argumentação do autor que a educação escolar contemporânea participaria desse processo de enfraquecimento das críticas ao capitalismo através das pedagogias do 'aprender a aprender'. Nelas é ensinado o 'saber fazer' tendo no horizonte a ocupação dos postos de trabalho das empresas capitalistas como fim da atividade educativa. A aprendizagem centrada no 'saber fazer' afasta o aprendiz do conhecimento da totalidade do real ao qual imanentemente este saber (e o próprio aluno) pertence esvaziando as possibilidades de emancipação humana, naturalizando as relações sociais necessárias ao modo de produção capitalista.

$\mathrm{O}$ autor examina quatro lemas das pedagogias do "aprender a aprender" por meio das quais, entendemos, seria possível explicitar seus motivos individualistas e idealistas que retiram do centro da causa dos problemas reais atuais o modo de produção capitalista. São eles (i) são mais desejáveis as aprendizagens que o indivíduo realiza por si mesmo, nas quais está ausente a transmissão, por outros indivíduos, de conhecimentos e experiências; (ii) é mais importante o aluno desenvolver um método de aquisição, elaboração, descoberta, construção de conhecimentos, do que aprender os conhecimentos que foram descobertos e elaborados por outras pessoas; (iii) a atividade do aluno, para ser verdadeiramente educativa, deve ser impulsionada e dirigida pelos interesses e necessidades dos próprios alunos e (iv) a educação deve preparar os indivíduos para acompanharem a sociedade em acelerado processo de mudança.

Entendemos que, orientada pelos quatro pontos acima, a educação escolar se volta para o desenvolvimento de competências que no máximo habilitem os aprendizes a ocuparem os postos de trabalho nos empreendimentos capitalistas (situação naturalizada pela escola), reforçado pelo individualismo no qual os objetivos educacionais implícitos nesses lemas conduzem. Objetivando a individualização do aprendiz esconde-se que há formas mais elevadas e desenvolvidas de conhecimentos, elaboradas historicamente pelo conjunto da humanidade. Essa individualização, concomitantemente, impõe uma 
fragmentação da classe trabalhadora, potencialmente revolucionária, enfraquecendo sua unidade de classe.

Destaca-se que, quanto ao objetivo das pedagogias do 'aprender a aprender' de 'desenvolver competências', o autor observa criticamente que esse objetivo sugere aos educadores conhecer a realidade social não para fazer a crítica a essa realidade e construir uma educação comprometida com as lutas por uma transformação social radical, mas sim para saber melhor quais competências a realidade social está exigindo dos indivíduos. Neste contexto, desenvolver a criatividade é desenvolver formas novas de se adaptar à realidade 'naturalizada' e não para transformá-la.

Após apresentar cinco motivos pelos quais acredita ser uma ilusão a alcunha de sociedade do conhecimento para nossa época, o autor, observa que, a assim chamada sociedade do conhecimento é uma ilusão. Ilusão que, por si mesma, é a fundamentação da atual sociedade capitalista. Esta ilusão desempenha uma função ideológica de enfraquecer as críticas radicais ao capitalismo e, consequentemente, enfraquecer a luta por uma revolução que leve a sua superação. Por isso, o capítulo é concluído com a seguinte citação marxiana "conclamar as pessoas a acabarem com as ilusões acerca de uma situação é conclamá-las a acabarem com uma situação que precisa de ilusões".

No segundo capítulo intitulado Relações entre ontologia e epistemologia e a reflexão filosófica sobre o trabalho educativo o autor aponta que o modelo epistemológico biologizante, como é o caso do modelo interacionista de base piagetiana, que fundamentaria as pedagogias do 'aprender a aprender', não é compatível com os fundamentos ontológicos de uma concepção histórico-social da formação dos seres humanos. Essa incompatibilidade decorre do entendimento de que sujeito e objeto são históricos, assim como a relação entre eles. A ausência dessa historicidade no modelo interacionismo-construtivista secundariza $\mathrm{o}$ ato de ensinar e de transmitir os conhecimentos historicamente elaborados pelas gerações humanas.

No entanto, afastar-se de uma postura biológica e naturalizante acerca do processo de conhecimento, e, assumir uma perspectiva histórico-social, não significa desconsiderar que a vida humana ou o processo de conhecimento se realizam de forma absolutamente independente dos processos naturais. Todavia, devemos reconhecer que houve um salto na evolução da vida sobre a terra: o salto da história da natureza orgânica para a história social. Este salto não estabelece uma ruptura com a condição natural do homem, mas configura o início de uma esfera ontológica qualitativamente nova enquanto realidade sócio-histórica. $\mathrm{O}$ fundamento objetivo para esse salto foi o trabalho enquanto atividade pelo qual o homem transforma a natureza e a si próprio, transformação recíproca que precisa ser compreendida mediante a dialética entre objetivação e apropriação.

$\mathrm{O}$ processo de apropriação decorre da relação entre o homem e a natureza ao incorporá-la a sua prática social através de atividades transformadoras. Ao mesmo tempo ocorre o processo de objetivação ao produzir uma realidade objetiva que passa a ser portadora de características humanas, acumulando a atividade de gerações de seres humanos. Isso gera a necessidade de outra forma de apropriação, não mais apenas como apropriação da natureza, mas também dos produtos culturais da atividade humana. Ou seja, o ser humano para satisfazer suas necessidades, cria uma realidade humana a partir da transformação tanto da natureza como do próprio ser humano e, ao produzir os meios para a satisfação de suas necessidades básicas de existência, ao produzir uma realidade humanizada pela sua atividade, o ser humano humaniza a si próprio, na medida em que a transformação objetiva requer dele uma transformação subjetiva. Tal dinâmica gera no homem necessidades de novo tipo que exigem nova atividade, num processo sem fim. 
Ao impor sua atividade criadora sobre a natureza objetivando-se em instrumentos e cultura, esses passam a conter uma síntese da atividade humana. Essa síntese deverá ser apropriada por todos os seres humanos que venham a incorporar qualquer objetivação à sua atividade individual. Essa incorporação/apropriação, e sua consequente inserção na atividade social, gera novas necessidades e novas forças, faculdades e capacidades. No entanto, a relação entre objetivação e apropriação não ocorre apenas quando o ser humano cria algo absolutamente novo. É preciso considerar que, a reprodução do ser social é um processo dialético no qual não se separam a criação do novo e a conservação do existente.

Voltando-se ao modelo interacionista-construtivista, o autor adverte que, os processos de difusão do conhecimento não podem ser analisados na perspectiva da existência de um abstrato sujeito cognoscente que interage com os objetos do conhecimento por intermédio de esquemas próprios da interação biológica que um organismo estabelece com o meio ambiente. Tanto na produção de um conhecimento socialmente novo, ou na apropriação dos conhecimentos existentes, a análise epistemológica precisa caracterizar justamente os elementos que configuram a inevitável historicidade da relação entre o sujeito e objeto.

Neste contexto, o trabalho educativo é fundamental. Por meio dele o individuo se apropria das objetivações sociais humanas, humanizando-se e, ao mesmo tempo, instrumentalizando-se para novas objetivações.

No capítulo três intitulado A anatomia do homem é a chave da anatomia do macaco: a dialética em Vigotski e em Marx e a questão do saber objetivo na educação escolar, o autor recoloca a importância do trabalho educativo como processo mediador da apropriação dos saberes mais desenvolvidos. Isto, porque, o desenvolvimento sociocultural do indivíduo é o desenvolvimento de um indivíduo histórico, situado na historia social humana. Para que esse desenvolvimento ocorra é necessário que ele se aproprie dos produtos culturais humanos mediatizado pelos adultos que já se apropriaram da mesma cultura. Processo que exige a interação entre adultos e crianças.

No caso dos conceitos científicos, Vigotski mostrou que ao serem ensinados à criança por meio da educação escolar, eles superaram por incorporação os conceitos cotidianos. Ou seja, o conhecimento do cotidiano não são descartados, eles operam como base para formação dos conhecimentos científicos que, por sua vez, reestrutura e modifica aqueles a partir de cima. Nesse sentido, a apreensão da realidade pelo pensamento não se realiza de forma imediata, pelo contato direto com as manifestações mais aparentes da realidade. Há que se desenvolver todo um complexo de mediações teóricas extremamente abstratas, porém materialistas, para se chegar à essência do real concreto em sua totalidade, em suas múltiplas determinações. Contudo, o processo de apropriação dos saberes elaborados historicamente pela humanidade ocorre a partir da realidade concreta capturada em sua síncrese, 'desce' as unidades constituintes, através de um movimento de síntese, e retorna à realidade concreta na síntese. $\mathrm{O}$ conhecimento resultante desse processo é a apropriação da realidade objetiva reproduzida no pensamento, de modo que, o concreto pensado se torna a apropriação dialética do concreto real. Não sendo o processo de apropriação e elaboração do conhecimento, portanto, desconectado do real concreto. Mas, de modo oposto, o movimento das categorias no pensamento é a expressão dos movimentos da realidade objetiva, exterior a esse pensamento de modo que, a análise da lógica de um determinado fenômeno na sua forma mais desenvolvida é a chave para a análise do processo histórico de desenvolvimento desse fenômeno.

O livro é concluído com o capítulo intitulado Ideal e Idealidade em Ilyenkov: contribuições para a reflexão filosófico-educacional Contemporânea no qual é apresentado um exame sobre ideal e idealidade a partir das considerações do filósofo 
soviético Evald Ilyenkov² ${ }^{2}$ O autor inicia a exposição argumentando que o termo ideal, no contexto de Ilyenkov, não é sinônimo de algo perfeito ou de uma causa a ser seguida e nem indica entidades pertencentes a um mundo separado e absolutamente distinto do mundo material. Ao contrário, ele diz respeito a uma esfera ideativa da realidade humana, isto é, àquilo que tem sua objetividade nas relações sociais, de modo que, o mundo das ideias é construído mediante a construção do mundo material humano. O que não significa que não existam concretamente, que não sejam objetivos.

No caso dos valores de uso e de troca das mercadorias, aquele seria consequência das características materiais particulares dela e, o valor de troca, o preço, o valor da mercadoria é distinta de sua forma corpórea real e tangível, é uma forma somente ideal ou imaginária. Entretanto, existe fora da consciência humana individual e independente dela, isto é, esse fenômeno ideal existe mesmo que os indivíduos não tenham conhecimento disso. Ou seja, o elemento ideativo não está expresso na materialidade da mercadoria, mas em algo situado no plano das relações sociais dos indivíduos e nas atividades que permite executar. A idealidade está contida, por exemplo, quando um ser humano troca uma quantidade de dinheiro por uma determinada mercadoria. O dinheiro existe como uma representação altamente abstrata de determinadas relações sociais. Assim o dinheiro tem uma existência ideal, mas totalmente objetiva visto que sua existência em nada depende de nossa consciência individual ou de vontade pessoal. O dinheiro tipifica, portanto, aquilo que poderia ser chamado de existência objetiva de algo que é ideal ou, simplesmente, objetividade da idealidade. Assim, a idealidade seria um aspecto importante da cultura humana, mas não apresentaria nenhum elemento transcendental. E, o mundo da consciência individual é construído com base na apropriação dessa idealidade existente nos fenômenos sociais.

Decorre que, no campo da educação, o ser humano precisa tornar-se senhor tanto da materialidade quanto da idealidade que constituem o mundo da cultura humana, o mundo criado pelo trabalho humano. Neste sentido, uma educação que se proponha a desenvolver a consciência autônoma dos indivíduos, teria como um de seus pressupostos o de que tal desenvolvimento não ocorre a não ser na atividade voltada para o exterior, para a realidade social, para o outro, por meio dos conhecimentos objetivados ao longo do trabalho humano que envolve, também, o âmbito da cultura, da idealidade.

Neste contexto, e a guisa de conclusão, entendemos que o objetivo do autor é mostrar a ilusão da afirmação amplamente divulgada de que vivemos na era do conhecimento. Para tanto é preciso considerar que o conhecimento ao qual o autor se refere é o conhecimento elaborado historicamente pelo conjunto da humanidade e não todo e qualquer conhecimento. Tendo esse entendimento no horizonte conectamos livremente os quatro textos componentes do livro em análise da seguinte forma.

Há uma realidade concreta objetiva, da qual pertencemos organicamente, com a qual lidamos no cotidiano e sobre a qual constituímos e construímos conhecimentos. Os conhecimentos objetivam-se nos instrumentos e na cultura social humana, na idealidade das relações sociais, e são elaborados historicamente pelo conjunto da humanidade. $\mathrm{O}$ papel da educação transformadora é (re)construir esses conhecimentos nas gerações seguintes, instrumentalizando-as para a transformação da sociedade e para a conquista de novos conhecimentos. De modo oposto, assumir que todos os saberes são válidos e possuidores do mesmo nível de desenvolvimento é pulverizar na humanidade uma concepção epistêmica fragmentária, em que 'tudo vale'. Entendemos, a partir da leitura do texto que, essa fragmentação decorre da necessidade que a classe burguesa, dominante do/no sistema capitalista de produção, possui de fragmentar a classe trabalhadora, potencialmente revolucionária, enfraquecendo sua unidade de classe. Essa fragmentação 
resultaria em uma alienação construída por um duplo movimento. De um lado no ensino escolar centrado no 'saber fazer' e, de outro, na suposição de que, por vivermos na era do conhecimento, qualquer saber trazido pelo aluno para o contexto escolar deve se tornar o centro do processo de ensino. Com isso aliena-se a classe trabalhadora do conhecimento dos saberes historicamente elaborados pela humanidade, sob o pretexto de que todos os saberes são equivalentes, subtraindo essa parcela da humanidade dos saberes necessários à sua emancipação.

\section{Notas}

\footnotetext{
${ }^{1}$ Professor do Programa de Educação da Universidade Federal do Oeste do Pará, Doutorando do Programa de Pós-graduação da Faculdade de Educação da Unicamp na área de concentração em Filosofia e História da Educação.

${ }^{2}$ Evald Vasilyevich Ilyenkov (1924-1979), filósofo soviético reconhecido pelos trabalhos originais o campo do desenvolvimento da lógica dialética materialista. Seus principais trabalhos incluem Dialectical Logic (1977), Leninist Dialectics and the Metaphysics of positivism (1982) and The Dialectics of the Abstract and Concrete in Marx's Capital (1982). Os dois últimos foram publicados postumamente após seu suicídio em 1979 (Fonte: http://www.marxists.org/glossary/people/i/l.htm\#ilyenkov-evald).
} 